\title{
Pelvic local recurrence as first relapse predicts prognosis for clinical stage II/III lower rectal cancer: A clinicopathological investigation
}

\author{
SHUJI UDA ${ }^{1}$, MASAYA MUKAI ${ }^{1}$, KYOKO KISHIMA ${ }^{1}$, DAIKI YOKOYAMA ${ }^{1}$, SAYURI HASEGAWA ${ }^{1}$, \\ TAKUYA KOIKE ${ }^{1}$, TAKAYUKI TAJIMA ${ }^{2}$, EIJI NOMURA ${ }^{1}$, KOUSUKE TOMITA ${ }^{3}$, TOMOHIRO MATSUMOTO ${ }^{3}$, \\ TERUMITSU HASEBE ${ }^{3}$ and HIROYASU MAKUUCHI ${ }^{1}$ \\ ${ }^{1}$ Department of Digestive Surgery, Tokai University Hachioji Hospital, Hachioji, Tokyo 192-0032; \\ ${ }^{2}$ Department of Surgery, Tokai University Tokyo Hospital, Shibuya, Tokyo 151-0053; \\ ${ }^{3}$ Department of Radiology, Tokai University Hachioji Hospital, Hachioji, Tokyo 192-0032, Japan
}

Received June 15, 2020; Accepted October 23, 2020

DOI: $10.3892 / \mathrm{mco} .2020 .2195$

\begin{abstract}
The present study investigated the association between the mode of tumor recurrence and prognosis in 123 patients with clinical stage II/III rectal cancer. In the past 10 years, patients received systemic chemotherapy following radical ( $\mathrm{R} 0$, with no macroscopic residual tumor lesions) resection using total or tumor-specific mesorectal excision. Patients with rectosigmoid cancer and $\mathrm{T} 4+$ chemoradiation therapy were excluded from the present study. The 5-year relapse-free survival rate (5Y-RFS), 5-year overall survival rate (5Y-OS), and associations between early post-operative complications, recurrence mode and prognosis, as well as the 5Y-OS of patients with relapsed cancer, were calculated. The overall 5Y-RFS and 5Y-OS were 71.4 and $83.5 \%$, respectively, and the overall recurrence rate was $22.8 \%$ (28/123 patients). Among relapses, remote metastases were observed in $17 / 123$ patients (13.8\%): The lung in 8 patients $(6.5 \%)$, the liver in 5 patients (4.1\%) and elsewhere in 4 patients (3.3\%). A total of 11 patients $(8.9 \%)$ had pelvic local recurrence as the first relapse, which was located anterior to the sacrum in 7 patients $(5.7 \%)$, at the anastomosis site in 2 patients (1.6\%), and in the inner pelvis in 2 patients (1.6\%). Among relapsed patients, the 5Y-OS was $69.3 \%$ in those with distant metastases and $27.3 \%$ in those
\end{abstract}

Correspondence to: Dr Shuji Uda, Department of Digestive Surgery, Tokai University Hachioji Hospital, Ishikawa-cho 1838, Hachioji, Tokyo 192-0032, Japan

E-mail: uda@is.icc.u-tokai.ac.jp

Abbreviations: CL, conventional laparotomy; CRT, chemoradiation therapy; HALS, hand-assisted laparoscopic surgery; PBLND, prophylactic bilateral lateral lymph node dissection; TME, total mesorectal excision; TSME, tumor specific mesorectal excision

Key words: rectal cancer, pelvic local recurrence, chemoradiation therapy, prophylactic bilateral lateral lymph node dissection, total mesorectal excision with local relapse $(\mathrm{P}=0.02$; no significant differences in patient demographics). The results indicated that advanced rectal cancer and control of pelvic local recurrence are manageable by $\mathrm{R} 0$ resection and postoperative chemotherapy. However, for patients whose initial relapse was pelvic local recurrence, the relapsed tumor initiated a new metastatic cascade to organs, such as the lung and liver, and affected prognosis.

\section{Introduction}

Among rectal cancers, rectosigmoid lesions are infrequently associated with pelvic local recurrence, and the recurrence mode and prognosis are similar to those of colorectal lesions $(1,2)$. But the survival of patients with advanced rectal cancer other than rectosigmoid cancer is considerably poorer than that of patients with colorectal cancer. In men, a narrow pelvis makes it difficult to perform surgical procedures in the deep pelvic floor. In addition, the circumferential resection margin, anal margin and scattering of tumor cells due to perforation during rectal surgery are reported to influence pelvic local recurrence (3). To improve the survival rate by reducing local recurrence, integrated approaches for advanced rectal cancer, such as preoperative chemoradiation therapy and intrapelvic prophylactic bilateral lymph node dissection (PBLND) have been conducted (4-11). Specifically, the Japanese Society for Cancer of the Colon and Rectum guidelines 2019 for the treatment of colorectal cancer (JSCCR guidelines 2019) (2) state that evidence is limited for preoperative chemoradiation improving survival rate, although it significantly reduces pelvic local recurrence. Indeed, few studies have reported an improvement in overall survival after preoperative chemoradiation $(2,12)$. Moreover, Japanese people are smaller than westerners and surgical outcome is relatively favorable. Therefore, chemoradiation has been conducted at a limited number of clinical sites in Japan (4-7). PBLND is effective for treating advanced lower rectal cancer, as reported in Japan $(8,9)$. In 2017, the final results of the JCOG0212 study, a randomized, multi-center study of PBLND, were announced. Statistical non-inferiority 
was not demonstrated in a longitudinal analysis of total mesorectal excision (TME) with or without PBLND, supporting the benefits of conventional PBLND $(10,11)$. However, although local recurrence rate was lower with PBLND, no differences were observed between 5-year relapse-free survival (5Y-RFS) or 5-year overall survival (5Y-OS), or the equivalent 10-year rates, in groups treated with or without PBLND. A retrospective study of 944 patients at Kurume University showed no significant difference in the survival rate but the prognosis was poor for patients with pathological (p)-stage IIIb cancer (9).

Our hospital did not introduce radiotherapy until 2010. In addition to a longer surgical time and more bleeding, PBLND is commonly associated with dysfunctions in bowel movement, urination and sexual function. Because of this, we have not conducted PBLND in our department. Instead, for patients with clinical (c)-stage II/III cancer, our standard treatment has been TME or tumor-specific mesorectal excision (TSME) to achieve radical resection with no macroscopic residual tumor postoperatively (R0), with postoperative adjuvant systemic chemotherapy (2,13-16). Currently, pre-operative chemoradiation for downsizing and downstaging advanced lower rectal cancer is selectively offered to patients in whom large T3/T4 tumors occupy the pelvic floor. Lateral lymph node dissection is conducted only on the side of the metastasis as demonstrated by pre-operative diagnostic imaging.

The purpose of this study was to clinicopathologically compare the overall survival, relapse rate and recurrence mode in patients with advanced (c-stage II/III) rectal cancer who received TME/TSME plus postoperative systemic chemotherapy. Pre-operative CRT/Lateral dissection/RS and T4 were excluded.

\section{Patients and methods}

Study design and patients. This retrospective, observational, single-center study was conducted over 10 years and 9 months (from April 2003 to December 2013) with approval by the Institutional Review Board (IRB no. 18R-331). It included 123 patients with advanced rectal cancer who underwent radical (R0) resection leaving no macroscopic residual tumor. Informed consent was obtained for every diagnostic or interventional procedure and the use of electronic medical records. Of the 123 participants, $79(64.2 \%)$ had c-stage II cancer and $44(35.8 \%)$ had c-stage III cancer (Table I). The presence or absence of metastasis ( $\geq 10 \mathrm{~mm}$ in the longest diameter) at the lateral lymph nodes was evaluated preoperatively using CT images interpreted by a radiologist, as per the JCOG0212 study (10). Patients with lateral lymph node metastasis or T4 multiple organ invasion (i.e. cases requiring chemoradiation) were excluded (6-9). Postoperative recurrence was evaluated three to four times a year using ultrasound (US) and computed tomography (CT) scans. For patients with at least two metastases (in the liver, lung, or locally), calculation of 5Y-OS in the recurrence group was based on the maximum area and the estimated volume by US/CT. The location that the larger value of the metastasis was judged as the first recurrence location. The location of the larger metastasis was recorded as the first recurrence location.
For patients with p-stage II cancer, the anti-cancer agent tegafur-uracil (UFT) was administered orally for 6-12 months postoperatively. Patients with p-stage III cancer received modified FOLFIRI chemotherapy (5-fluorouracil + leucovorin) for 6 months, followed by oral UFT for at least 6 months (6-9). Excluding rectosigmoid lesions, the tumor was located above the peritoneal reflection $(\mathrm{Ra})$ in 61 patients $(49.6 \%)$ and below $(\mathrm{Rb})$ in 62 patients $(50.4 \%)$. The median distance from the anal verge was $2.5 \mathrm{~cm}$ (range, $0.5-12.0 \mathrm{~cm}$; mean, $3.3 \mathrm{~cm}$ ) (Table I). Operative methods were low anterior resection in 89 patients (72.4\%), the Miles operation in 31 patients $(25.2 \%)$ and other methods in 3 patients $(2.4 \%)$. Conventional laparotomy (CL) was conducted in 55 patients $(44.7 \%)$ and hand-assisted laparoscopic surgery (HALS) was conducted in 68 patients (55.3\%) (Table I) (6-9). Pathological T category distributions were as follows: T2, 36 patients $(29.3 \%)$; T3, 74 patients $(60.2 \%)$; others, 13 patients $(10.6 \%)$. Pathological $\mathrm{N}$ category distributions were as follows: N0, 70 patients $(56.9 \%)$; N1, 45 patients (36.6\%); others, 8 patients $(6.5 \%)$ (Table II). Forty-two patients (34.1\%) had p-stage II cancer, $53(43.1 \%)$ had p-stage III, and 28 (22.8\%) had cancers classed as other stages. Of all resections, 118 (95.9\%) were R0 and 5 (4.1\%) were R1 (Table II).

Operations and procedures. CL was standard midline laparotomy. For HALS, a small incision of $50 \mathrm{~mm}$ was created for hand access. In accordance with the JSCCR guidelines 2019 (2) and classification of colorectal carcinoma (17), central vascular ligation was conducted at the root of the inferior mesenteric artery as distal D3 lymph node dissection or left colic artery-preserving D2 ligation (17-20). TME was conducted for rectosigmoid tumors by transection of the mesorectum immediately above the aortic bifurcation. Lateral dissection was performed from the anterior sacrum to the medial region of the bilateral internal iliac artery. TME was also conducted from the anterior region of the pelvic floor muscles and from the lower part of the bladder to the posterior face of the prostate or the rear wall of the vagina (18). Patients with Ra rectal cancer underwent TSME. After securing a minimum safety margin of approximately $20 \mathrm{~mm}$ from the posterior face of the tumor to the anal side, the lower rectum was clamped. Then, the inner part of the rectum was carefully washed, and the incision was anastomosed and closed using the double-staple technique (21).

5Y-RFS and 5Y-OS were calculated for patients with c-stage II/III cancer. Early post-operative complication rate was evaluated using the National Cancer Institute's Common Terminology Criteria for Adverse Events version 4.0, and the correlation between recurrence modes and prognosis was investigated. 5Y-OS was also calculated for the group of patients whose tumors recurred.

Statistical analysis. We retrospectively evaluated operation time, blood loss, postoperative morbidity (grade 3 or 4), and hospital mortality. 5Y-RFS and 5Y-OS were obtained by Kaplan-Meier estimation and log-rank test. Pearson's Chi-square test, Fisher's exact test and the Mann-Whitney U test were used to compare patient demographics. Statistical analysis was conducted using IBM SPSS Statistics for Windows Version 25.0 (IBM Corp.) and $\mathrm{P}<0.05$ was considered significant. 
Table I. Demographic characteristics of the study population.

\begin{tabular}{|c|c|}
\hline Characteristics & Value \\
\hline Total undergoing TME/TSME, n & 123 \\
\hline \multicolumn{2}{|l|}{$\operatorname{Sex}, \mathrm{n}(\%)$} \\
\hline Male & $86(69.9)$ \\
\hline Female & $37(30.1)$ \\
\hline \multicolumn{2}{|l|}{ Age, years } \\
\hline Median (range)/mean & $67(36-92) / 67$ \\
\hline \multicolumn{2}{|l|}{ Clinical stage, n (\%) } \\
\hline II & $79(64.2)$ \\
\hline III & $44(35.8)$ \\
\hline \multicolumn{2}{|l|}{$\begin{array}{l}\text { Tumor location without rectosigmoid } \\
\text { lesion, } \mathrm{n}(\%)\end{array}$} \\
\hline $\mathrm{Ra}$ (above the peritoneal reflection) & $61(49.6)$ \\
\hline $\mathrm{Rb}$ (below the peritoneal reflection) & $62(50.4)$ \\
\hline \multicolumn{2}{|l|}{ Tumor distance from anal verge, $\mathrm{cm}^{\mathrm{a}}$} \\
\hline Median (range)/mean & $2.5(0.5-12) / 3.3$ \\
\hline \multicolumn{2}{|l|}{ Tumour size, n (\%) } \\
\hline$\leq 5 \mathrm{~cm}$ & $70(56.9)$ \\
\hline$>5 \mathrm{~cm}$ & $53(43.1)$ \\
\hline \multicolumn{2}{|l|}{ Type of surgery (D2/D3 resection), n (\%) } \\
\hline Anterior resection & $1(0.8)$ \\
\hline Low anterior resection & $89(72.4)$ \\
\hline $\begin{array}{l}\text { Abdominoperineal resection } \\
\text { (Miles' operation) }\end{array}$ & $31(25.2)$ \\
\hline Hartmann's procedure & $2(1.6)$ \\
\hline \multicolumn{2}{|l|}{ Surgical method, n (\%) } \\
\hline Conventional laparotomy & $55(44.7)$ \\
\hline Hand-assisted laparoscopic surgery & $68(55.3)$ \\
\hline
\end{tabular}

${ }^{a}$ Data for 10 patients are missing (no pathological measurement with indistinct images). TME, total mesorectal excision; TSME, tumor-specific mesorectal excision.

\section{Results}

Survival rates. The 5Y-RFS rate was $71.4 \%$ (95\% confidence interval [CI]: 63.4-79.4) (Fig. 1) and 5Y-OS rate was $83.5 \%$ (95\% CI: 76.9-90.1). The follow up rate for both estimates was $94.3 \%$ (Fig. 2).

Complication rates. Grade 3-4 postoperative complications were observed in 12 patients (9.8\%); anastomotic leakage in 9 patients $(7.3 \%)$; urinary retention or injury in 7 patients $(5.7 \%)$; pelvic abscess in 5 patients $(4.1 \%)$; and wound infection in 33 patients $(26.9 \%)$. The 33 patients with wound infection comprised $17(44.7 \%)$ of the 38 patients who had undergone CL, and $16(30.8 \%)$ of the 52 patients who had undergone HALS, with no significant difference between operative method ( $\mathrm{P}=0.358$, Pearson's Chi-square test). All wound infections were grades 1 or 2 and healed fully after conservative treatment (Table III).
Table II. Clinicopathological features of the study population.

\begin{tabular}{ll}
\hline Clinicopathological feature Value \\
\hline
\end{tabular}

Total undergoing TME/TSME, $\mathrm{n}$

123

Time, min

Median (range)/mean

$230(88-432) / 243$

Blood loss, $\mathrm{ml}$

Median (range)/mean

$439(5-4293) / 569$

Pathological T category, n (\%)

pT1

4 (3.2)

pT2

pT3

$36(29.3)$

$74(60.2)$

pT4

$9(7.3)$

Pathological N category, n (\%)

$\mathrm{pNO}$

$70(56.9)$

pN1

45 (36.6)

$\mathrm{pN} 2$

$7(5.7)$

$1(0.8)$

Pathological stage, n (\%)

I

$27(22.0)$

$42(34.1)$

$53(43.1)$

III

$1(0.8)$

Pathological residual tumor, n (\%)

R0

$118(95.9)$

$\mathrm{R} 1$

$5(4.1)$

$0(0)$

TME, total mesorectal excision; TSME, tumor-specific mesorectal excision.

Recurrence rates. Recurrence occurred in 28/123 patients (22.8\%). Distant metastases occurred in $17 / 123$ patients (13.8\%), of whom 8 (6.5\%) had metastasis in the lung, 5 (4.1\%) in the liver, and 4 (3.3\%) elsewhere (Table IV). Local recurrence occurred in $11 / 123$ patients $(8.9 \%)$, of whom $7(5.7 \%)$ had metastasis anterior to the sacrum, $2(1.6 \%)$ at the anastomosis, and $2(1.6 \%)$ in the medial part of the pelvis (Table IV).

Survival rate of patients with relapsed tumors. The 5Y-OS rate for patients whose cancer had recurred was $69.3 \%$ in the 17 patients with remote metastasis and $27.3 \%$ in the 11 patients with local recurrence $(\mathrm{P}=0.02)$, from a follow-up rate of $92.9 \%$ (Fig. 3). No significant differences were observed in patient demographics between local recurrence and distant metastasis (Table V).

\section{Discussion}

The prognosis following rectal cancer surgery is considerably poorer than after colon cancer, for the following possible reasons: i) The pelvic cavity narrows toward the anal region, making surgery difficult and pelvic local recurrence relatively common (3). ii) Preoperative chemoradiation and PBLND 


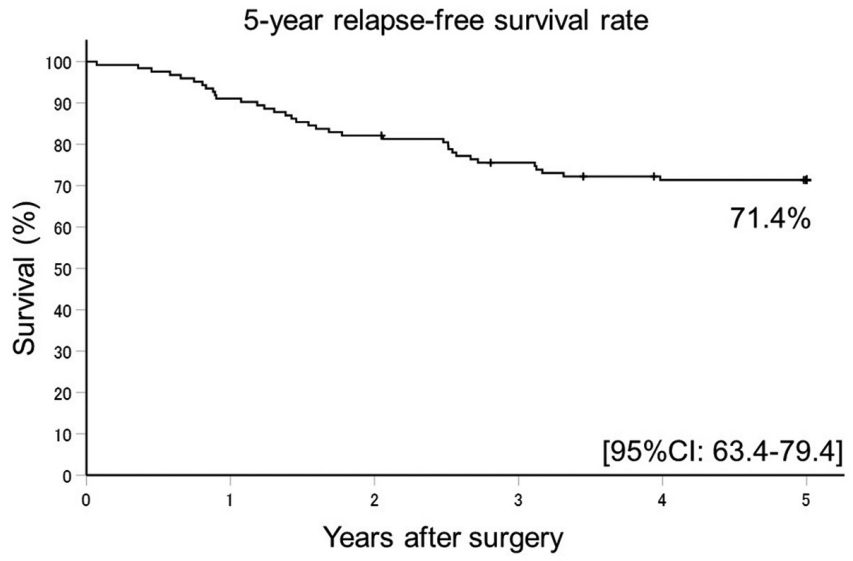

Figure 1. Five-year relapse-free survival rate for advanced rectal cancer (clinical stage II/III). n=123; follow-up rate, 94.3\%. CI, confidence interval.

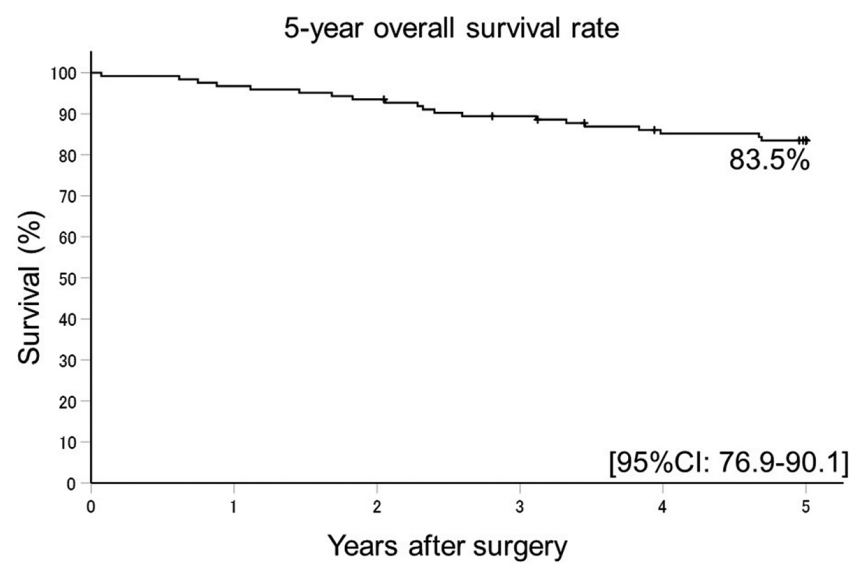

Figure 2. Five-year overall survival rate for advanced rectal cancer (clinical stage II/III). $\mathrm{n}=123$; follow-up rate, $94.3 \%$. CI, confidence interval.

are conducted to lower the rate of recurrence and improve survival but, although these preoperative treatments significantly lower local recurrence rate, there is little evidence that they improve survival rate. These two reasons do not seem to add up at present (4-11). An alternative approach could be to control fatal hematogenous metastasis in the lung and liver, which may be more beneficial than reducing local recurrence in extending progression-free and overall survival rates $(3,18,19)$. However, in the present study, the prognosis of the remote metastasis group was better than that of the local recurrence group. Remote metastatic lesions can be resected and re-resected without negatively affecting quality of life. In addition, a variety of treatment options exist, from first-line to later-line chemotherapy, and radiofrequency ablation for liver metastasis, which may explain the present results.

In contrast, for pelvic local recurrence, R0 re-resection while preserving quality of life is often difficult. Some success has been achieved with sacrococcygeal resection and total removal of the bladder and prostate (double stoma), but treatment options other than surgical re-resection and chemoradiation are limited. Furthermore, in the present study, when pelvic recurrence occurred first, the prognosis was very poor. Seven of eleven cases had local recurrence with distant secondary metastasis (lung metastasis: 6 cases, both lung and
Table III. Adverse events.

Adverse event

Number $(\%)$

Any grade 3-4 complication ${ }^{\mathrm{a}}$

$12(9.8)$

Anastomotic leakage ${ }^{\mathrm{b}}$

$9(10.0)$

Urinary retention/injury

7 (5.7)

Hemorrhage after surgery

$0(0)$

Wound infection

Pelvic abscess

Bowel obstruction

$13(10.6)$

Others ${ }^{c}$

$10(8.1)$

${ }^{a}$ National Cancer Institute-Common Toxicity Criteria Version 4.0; ${ }^{\mathrm{b}}$ number of patients with anastomoses, $\mathrm{n}=90$; ' others: Myocardial infarction/angina, MRSA/sepsis, femoral dysesthesia. TME, total mesorectal excision; TSME, tumor-specific mesorectal excision.

Table IV. Patterns of recurrence.

\begin{tabular}{lc}
\hline Recurrence & Number $(\%)$ \\
\hline Total recurrence rate & $28(22.8)$ \\
Distant metastasis & $17(13.8)$ \\
Lung & $8(6.5)$ \\
Liver & $5(4.1)$ \\
Others & $4(3.3)$ \\
Peritoneal dissemination & $3(2.4)$ \\
Inguinal lymph node & $1(0.8)$ \\
Local pelvic recurrence & $11(8.9)$ \\
Median presacral & $7(5.7)$ \\
Anastomosis & $2(1.6)$ \\
Pelvic lateral lymph node & $2(1.6)$ \\
\hline
\end{tabular}

$\mathrm{n}=123$.

liver metastasis: 1 case). There were no distant metastasis cases with secondary local recurrence case $(0 / 17)$. In the 11 patients with pelvic local recurrence, six cases occurred within 2.5 years, and two occurred in less than 1 year. Three patients had late local recurrence that occurred after 2.5 years. Remote metastasis after chemoradiation was fatal. The two patients who experienced anastomotic recurrence underwent a second Miles operation, which helped control local lesions. The prognosis of local recurrence is generally favorable. But pelvic local recurrence that occurs relatively soon after surgery (within 2.5 years) may initiate a new metastatic cascade to the lung, liver and other organs, with malignant potential. Therefore, we recommend a large-scale survival analysis in patients whose first relapse is pelvic local recurrence, and the adoption of MRI and FDG-PET should be considered over CT $(12,22)$.

Recently, pre-operative chemoradiation for lower rectal cancer has become popular in Japan (4-7). However, in secondary cancers, such as metachronous prostate and uterine cancer, which are becoming more prevalent due to an aging society, treatment options may be limited. Moreover, 
Table V. Clinical backgrounds of patients with distant and local recurrence.

\begin{tabular}{|c|c|c|c|c|}
\hline Variable & $\begin{array}{l}\text { Total cases } \\
\qquad(n=28)\end{array}$ & $\begin{array}{l}\text { Distant metastasis } \\
\qquad(\mathrm{n}=17)\end{array}$ & $\begin{array}{l}\text { Pelvic local recurrence } \\
\qquad(\mathrm{n}=11)\end{array}$ & P-value \\
\hline Sex, n $(\%)$ & & & & $0.191^{\mathrm{a}}$ \\
\hline Male & $21(75.0)$ & $11(64.7)$ & $10(90.9)$ & \\
\hline Female & $7(25.0)$ & $6(35.3)$ & $1(9.1)$ & $>0.999^{\mathrm{b}}$ \\
\hline Age, years; median (range) & $70(44-86)$ & $70(44-86)$ & $70(46-81)$ & \\
\hline Tumor location, n (\%) & & & & $>0.999^{\mathrm{a}}$ \\
\hline $\mathrm{Ra}$ & $9(32.1)$ & $6(35.3)$ & $3(27.3)$ & \\
\hline $\mathrm{Rb}$ & $19(67.9)$ & $11(64.7)$ & $8(72.7)$ & \\
\hline Clinical stage, n (\%) & & & & $0.404^{\mathrm{b}}$ \\
\hline II & $12(42.9)$ & $6(35.3)$ & $6(54.5)$ & \\
\hline III & $16(57.1)$ & $11(64.7)$ & $5(45.5)$ & \\
\hline
\end{tabular}

${ }^{\mathrm{a}}$ Fisher's exact test; ${ }^{\mathrm{b}}$ Mann-Whitney U test.

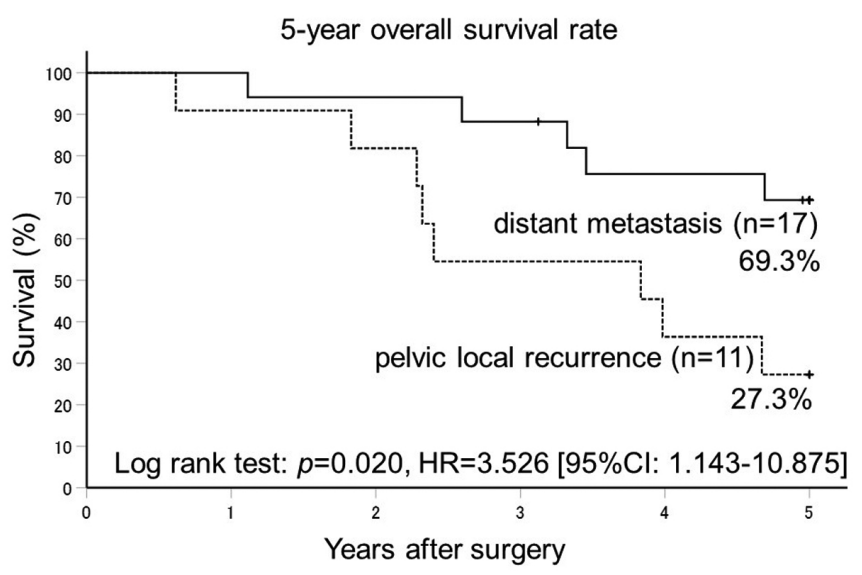

Figure 3. Five-year overall survival rate for patients with advanced rectal cancer (clinical stage II/III) and recurrence. $\mathrm{n}=28$; follow-up rate, $92.9 \%$. $\mathrm{HR}$, hazard ratio; CI, confidence interval.

after pre-operative chemoradiation, the disease is already at a clinical stage. The pathological staging system by which stage II/III is determined is based on the Dukes classification, and has no category for the presence or absence of metastasis to lymph nodes. In addition, the number of metastases to lymph nodes cannot be calculated accurately (20). PBLND, which is uniquely conducted in Japan for controlling local relapse, does not affect survival rate. The JCOG0212 study showed that the lateral lymph node metastasis rate was $15.4 \%$ (4/26 patients) after lymph node dissection. The most common central pelvic, anterior to the sacrum, recurrence was $27.3 \%$ (12/44 patients) in that study's TME-only group and $42.3 \%$ (11/26 patients) in the group that also underwent lateral lymph node dissection. Non-inferiority was not demonstrated for 7-year progression-free survival $(\mathrm{P}=0.064)(10,11)$. Therefore, although preoperative chemoradiation and PBLND lower the local recurrence rate, the decision to use these approaches must be decided after careful consideration of functional impairment, adverse reactions, and treatment options after recurrence.
Full-endoscopic surgery has become popular in Japan in recent years. However, for operating on advanced lower rectal cancer, complications relating to the dissection margin at the posterior and rectal side of the tumor have been observed using this technique $(23,24)$. Accordingly, in 2007, we began developing HALS, a hybrid technique between standard laparotomy and full-endoscopic surgery, and have reported favorable outcomes $(18,25,26)$. Three-port HALS for rectal cancer achieved better results than standard laparotomy (18). Requiring only a small incision of approximately $50 \mathrm{~mm}$, HALS is considered a sound technique, characterized by low invasiveness, low risk, low cost, and good outcomes. In addition, it places less burden on patients, doctors and hospitals than standard laparotomy $(18,25,26)$. Three intra-operative factors can lower the rate of pelvic local recurrence: i) Maintaining a thick resection margin $(>1 \mathrm{~mm}$ ) around the tumor, which must be avoided so as not to disperse cancer cells into the intestine by perforating the tumor during surgery. In men with tumors at the anterior wall of the lower rectum, the prostate is present and it is not easy to ensure such a thick margin. Combined resection may carry a high risk of bleeding and functional impairment. In women, partial combined resection of the posterior vaginal wall may be effective. Male patients with $\mathrm{Rb}$ anterior wall rectal cancer with a resection margin of $\leq 1 \mathrm{~mm}$ are considered at high risk of local recurrence. In the present study, we identified no cases of recurrence from the lower part of the bladder to the nearby area of the prostate. ii) Pelvic local recurrence occurred in the anterior part of the sacrum in $7 / 11$ patients $(63.6 \%)$ in the present study. TME/TSME using layer-by-layer surgery from the anterior region to the internal iliac artery region was considered the most important procedure for avoiding recurrence. Specifically, for male patients with a small pelvic cavity and high body mass index, HALS was considered suitable for dissection anterior to the sacrum. By using the left hand to apply strong traction to the rectum, pulling it towards the outside of the pelvic cavity to enlarge the endoscopic view, accurate TME/TSME can be conducted for sharp dissection from the region anterior to the sacrum 
and to expose the posterior wall of the rectum. We observed a better survival rate for HALS than for CL in the present study (data not shown: 5Y-RFS, $\mathrm{P}=0.166$; 5Y-OS, $\mathrm{P}=0.013$ ). iii) Careful intraoperative washing of the anorectal area prior to dissection is important. To avoid mechanical implantation of cancer cell clusters in the rectum upon dissection, iodine and physiological saline washes and aspiration must be conducted under endoscopy. In addition, an anal-side stump length of $\geq 20 \mathrm{~mm}$ should be retained if possible (21). Together, these factors will contribute to the prevention of local recurrence. For patients at high risk of pelvic recurrence, such as those with massive lymph node metastasis ( $>$ N2b) and anterior sacrum R1, postoperative pathological staging (without modification by radiation therapy) indicates that an integrated approach consisting of aggressive combination therapy, such as the early use of a molecular target drug and radiotherapy to the pelvic floor or anterior sacrum, is considered effective.

The prognosis becomes poor if postoperative complications occur in patients with lower rectal cancer. Among patients with early postoperative complications in this study, wound infection was most common (33/123 patients; $26.8 \%$ ). With CL, the rate was $17 / 55$ patients (30.9\%) (27), but the infections we observed in the present study were mild (grades 1-2). Together, the present and previous data indicate that to improve relapse-free and overall survival, the following points should be adhered to: i) During surgery, to prevent local recurrence, a HALS-based low-invasiveness R0 resection should be conducted. A 'one surgery, one chance' approach could reduce postoperative complications; ii) shortly after surgery (1-2 months), postoperative adjuvant chemotherapy should be conducted for 6 months $(18,19)$. In conclusion, advanced rectal cancer and control of local pelvic recurrence are manageable by $\mathrm{R} 0$ resection and postoperative multi-combinational chemotherapy. However, for patients whose initial relapse is pelvic recurrence, the relapsed tumor initiated a new metastatic cascade to distant organs and significantly affected prognosis.

\section{Acknowledgements}

Not applicable.

\section{Funding}

No funding was received.

\section{Availability of data and materials}

The datasets used and/or analyzed during the current study are available from the corresponding author on reasonable request.

\section{Authors' contributions}

SU and DY performed the research for the present study, contributed to data analysis and wrote the manuscript. MM, HM and TT designed the research for the present study, provided surgical advice and supervised the present study. KK, SH and TK analyzed the data. KT, TM, and TH diagnosed and judged the radiological findings, particularly the CT exami- nations. EN acquired the surgical data. All authors read and approved the final manuscript.

\section{Ethics approval and consent to participate}

Ethics approval was provided by the Research and Study Program of Tokai University Educational System General Research Organization (IRB no. 18R-331). Written informed consent to participate was obtained from all patients and/or their family members.

\section{Patient consent for publication}

Written informed consent for publication of the present study was obtained from the patients and/or family members.

\section{Competing interests}

The authors declare that they have no competing interests.

\section{References}

1. Mukai M, Kishima K, Yamazaki M, Aoki H, Izumi H, Yamamoto S, Tajima T, Tobita K, Sadahiro S, Yasuda S and Ogoshi K: Stage II/III cancer of the rectosigmoid junction: An independent tumor type? Oncol Rep 26: 737-741, 2011.

2. Hashiguchi Y, Muro K, Saito Y, Ito Y, Ajioka Y, Hamaguchi T, Hasegawa $\mathrm{K}$, Hotta $\mathrm{K}$, Ishida $\mathrm{H}$, Ishiguro $\mathrm{M}$, et al: Japanese Society for Cancer of the Colon and Rectum(JSCCR) guidelines 2019 for the treatment of colorectal cancer. Int J Clin Oncol 25: $1-42,2019$.

3. Mukai M, Nakamura M, Kishima K, Ninomiya H, Nomura N, Sato H, Kato N, Machida T, Nakasaki H and Makuuchi H: Local recurrence and occult neoplastic cells in the extranodal fat of dissected lymph nodes in patients with curatively resected primary colorectal cancer. Oncol Rep 17: 1365-1369, 2007.

4. Cammà $\mathrm{C}$, Giunta $\mathrm{M}$, Fiorica $\mathrm{F}$, Pagliaro L, Craxì $\mathrm{A}$ and Cottone M: Preoperative radiotherapy for resectable rectal cancer. A meta-analysis. JAMA 284: 1008-1015, 2000.

5. Colorectal Cancer Collaborative Group: Adjuvant radiotherapy for rectal cancer: A systematic overview of 8,507 patients from 22 randomised trials. Lancet 358: 1291-1304, 2001.

6. Bosset JF, Collete L, Calais G, Mineur L, Maingon P, Radosevic-Jelic L, Daban A, Bardet E, Beny A and Ollier JC; EORTC Radiotherapy Group Trial 22921: Chemotherapy with preoperative radiotherapy in rectal cancer. N Engl J Med 355: 1114-1123, 2006.

7. Gérard JP, Conroy T, Bonnetain F, Bouché O, Chapet O, Closon-Dejardin MT, Untereiner M, Leduc B, Francois E, Maurel J, et al: Preoperative radiotherapy with or without concurrent fluorouraciland leucovorin in T3-4 rectal cancers: Results of FFCD 9203. J Clin Oncol 24: 4620-4625, 2006.

8. Ozawa H, Kotake K, Hosaka M, Hirata A and Sugihara K: Impact of lateral pelvic lymph node dissection on the survival of patients with T3 and T4 low rectal cancer. World J Surg 40: 1492-1499, 2016.

9. Kinugasa T, Akagi Y and Shirouzu K: Benefit of lateral lymph node dissection for rectal cancer: Long-term analysis of 944 cases undergoing surgery at a single center (1975-2004). Anticancer Res 34: 4633-4639, 2014.

10. Fujita S, Mizusawa J, Kanemitsu Y, Ito M, Kinugasa Y, Komori K, Ohue M, Ota M, Akazai Y, Shiozawa M, et al: Mesorectal excision with or without lateral lymph node dissection for clinical stage II/III lower rectal cancer (JCOG0212): A multicenter, randomized controlled, noninferiority trial. Ann Surg 266: 201-207, 2017.

11. Tsukamoto S, Fujita S, Ota M, Mizusawa J, Shida D, Kanemitsu Y, Ito M, Shiomi A, Komori K, Ohue M, et al: Long-term follow-up of the randomized trial of mesorectal excision with or without lateral lymph node dissection in rectal cancer (JCOG0212). Br J Surg 107: 586-594, 2020. 
12. Folkesson J, Birgisson H, Pahlman L, Cedermark B, Glimelius B and Gunnarsson U: Swedish rectal cancer trial: Long lasting benefits from radiotherapy on survival and local recurrence rate. J Clin Oncol 23: 5644-5650, 2005.

13. Mukai M, Tajima T, Nakasaki H, Sato S, Ogoshi K and Makuuchi H: Efficacy of postoperative adjuvant oral immunochemotherapy in patients with Dukes' B colorectal cancer. Ann Cancer Res Ther 11: 201-214, 2003.

14. Lembersky BC, Wieand HS, Petrelli NJ, O'Connell MJ, Colangelo LH, Smith RE, Seay TE, Giguere JK, Marshall ME, Jacobs AD, et al: Oral uracil and tegafur plus leucovorin compared with intravenous fluorouracil and leucovorin in stage II and III carcinoma of the colon: Results from National Surgical Adjuvant Breast and Bowel Project Protocol C-06. J Clin Oncol 24: 2059-2064, 2006.

15. Ito I, Mukai M, Ninomiya H, Kishima K, Tsuchiya K, Tajima T, Oida Y, Nakamura M and Makuuchi H: Comparison between intravenous and oral postoperative adjuvant immunochemotherapy in patients with stage II colorectal cancer. Oncol Rep 20: 1189-1194, 2008

16. Mukai M, Okada K, Fukumitsu H, Yazawa N, Hoshikawa T, Tajima T, Hirakawa H, Ogoshi K and Makuuchi H: Efficacy of 5-FU/LV plus CPT-11 as first-line adjuvant chemotherapy for stage IIIa colorectal cancer. Oncol Rep 22: 621-629, 2009.

17. Japanese Society for Cancer of the Colon and Rectum. Japanese Classification of Colorectal, Appendiceal, and Anal Carcinoma. 9th edition. Kanehara Shuppan Co. Ltd., Tokyo, pp21-27, 2018.

18. Tajima T, Mukai M, Koike T, Yokoyama D, Uda S, Yoshii H, Higami S, Izumi H, Hasegawa S, Nomura E and Makuuchi H: Better survival after hand-assisted laparoscopic surgery than conventional laparotomy for rectal cancer: Five year results from a single center in Japan. Clin Surg 2: 1368, 2017.

19. Mukai M, Tajima T, Hasegawa S, Yokoyama D, Koike T, Hiraiwa S, Sugiyama T and Tajiri T: Recent molecular immunological chemotherapy for gastrointestinal malignancies. Clin Oncol 2: 1233, 2017.

20. Dukes CE: The classification of cancer of the rectum. J Pathol (Bacteriol) 35: 323-332, 1932.

21. Furuhata T, Hata F, Tsuruma T, Nshimori H, Yamaguchi $K$, Mizuguchi T, Kimura Y, Katsuramaki T, Mukaiya M, Sasaki K and Hirata K: Endo-Bowel clamp (PL540S) for safe rectal irrigation in laparoscopy-assisted rectal resection. Surg Today 34 882-884, 2004
22. Cerny M, Dunet, V, Prior JO, Hahnloser D, Wagner AD, Meuli RA and Schmidt S: Initial staging of locally advanced rectal cancer and regional lymph nodes comparison of diffusion-weighted MRI with 18F-FDG-PET/CT. Clin Nucl Med 41: 289-295, 2016.

23. Fleshman J, Branda M, Sargent DJ, Boller AM, George V, Abbas M, Peters WR Jr, Maun D, Chang G, Herline A, et al: Effect of laparoscopic-assisted resection vs. open resection of stage II or III rectal cancer on pathologic outcomes: The ACOSOG Z6051 randomized clinical trial. JAMA 314: 1346-1355, 2015.

24. Stevenson AR, Solomon MJ, Lumley JW, Hewett P, Clouston AD, Gebski VJ, Davies L, Wilson K, Hague W and Simes J; ALaCaRT Investigators: Effect of laparoscopic-assisted resection vs. open resection on pathological outcomes in rectal cancer: The ALaCaRT randomized clinical trial. JAMA 314: 1356-1363, 2015.

25. Mukai M, Kishima K, Tajima T, Hoshikawa T, Yazawa N, Fukumitsu H, Okada K, Ogoshi K and Makuuchi H: Efficacy of hybrid 2-port hand-assisted laparoscopic surgery (Mukai's operation) in patients with colorectal cancer. Oncol Rep 22: 893-899, 2009.

26. Tajima T, Mukai M, Yokoyama D, Higami S, Uda S, Hasegawa S, Nomura E, Sadahiro S, Yasuda S and Makuuchi H: Comparison of hand-assisted laparoscopic surgery (HALS) and conventional laparotomy in patients with colorectal cancer: Final results from a single center. Oncol Lett 13: 4953-4958, 2017.

27. Kitano S, Inomata M, Mizusawa J, Katayama H, Watanabe M, Yamamoto S, Ito M, Saito S, Fujii S, Konishi F, et al: Survival outcomes following laparoscopic versus open D3 dissection for stage II or III colon cancer (JCOG0404): A phase 3, randomized controlled trial. Lancet Gastroenterol Hepatol 2: 261-268, 2017.

This work is licensed under a Creative Commons Attribution-NonCommercial-NoDerivatives 4.0 International (CC BY-NC-ND 4.0) License. 